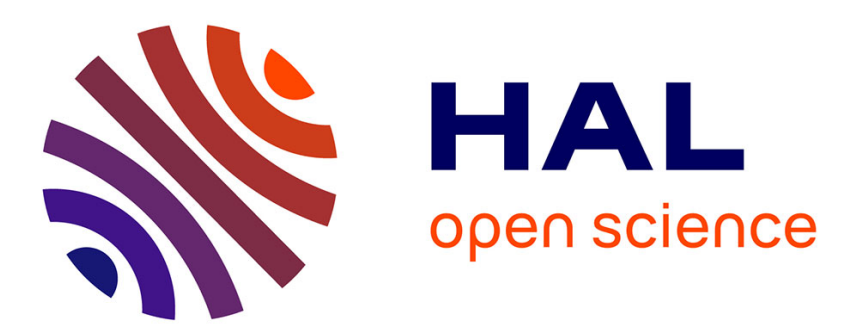

\title{
Effects of Exposure to Chicks on Maternal Behaviour in Domestic Chickens
}

\author{
Marie-Annick Richard-Yris, Gérard Leboucher
}

\section{To cite this version:}

Marie-Annick Richard-Yris, Gérard Leboucher. Effects of Exposure to Chicks on Maternal Behaviour in Domestic Chickens. Bird Behavior, 1987, 7, pp.31-36. 10.3727/015613887791918150 . hal-01327746

\section{HAL Id: hal-01327746 https://hal-univ-rennes1.archives-ouvertes.fr/hal-01327746}

Submitted on 5 Sep 2019

HAL is a multi-disciplinary open access archive for the deposit and dissemination of scientific research documents, whether they are published or not. The documents may come from teaching and research institutions in France or abroad, or from public or private research centers.
L'archive ouverte pluridisciplinaire HAL, est destinée au dépôt et à la diffusion de documents scientifiques de niveau recherche, publiés ou non, émanant des établissements d'enseignement et de recherche français ou étrangers, des laboratoires publics ou privés. 


\title{
Effects of Exposure to Chicks on Maternal Behaviour in Domestic Chickens
}

\author{
Marie A. Richard-Yris and G. Leboucher \\ Laboratoire d'Ethologie, UA 373, Avenue du Général Leclerc, 35042 Rennes cédex, France
}

\begin{abstract}
RICHARD-YRIS, M.A. and G. LEBOUCHER. 1987. Effects of exposure to chicks on maternal behaviour in domestic chickens. Bird Behaviour 7:31-36.

Two different procedures were followed to induce maternal behaviour in domestic hens. When chicks were placed under hens during the night, the majority of adults presented maternal behaviour the following morning. When chicks were placed in cages at the beginning of the photophase, maternal responses appeared after a $24 \mathrm{~h}$ delay; hens first avoided or were aggressive towards chicks. The results are discussed in terms of hens becoming familiar with auditory, tactile and visual stimuli from chicks.
\end{abstract}

Hen Maternal behaviour Night presentation Day presentation

\section{Introduction}

The appearance of maternal behaviour, essential in birds and mammals for the survival and normal development of young, is related to the optimal coincidence of specific physiological states and stimuli $(5,8$, 10 ). This behaviour can be induced outside the normal phase of the reproductive cycle by artificially recreating physiological states and stimulating situations. The responses of treated animals closely resemble parental responses observed under natural conditions $(14,16)$.

Stimuli from the young are essential factors in the regulation of these behaviours; they can be very diverse (tactile, auditory, olfactory or visual), and can have either positive or negative consequences on the development and on maintenance of maternal behaviour. Odors of young delay the appearance of parental responses in non-parturient rats (12), whereas they facilitate the establishment of a selective attachment between an ewe and her lamb (13). In birds, many authors have stressed the influence of auditory stimuli produced by embryos towards the end of incubation on the regulation of parental responses in brooding animals $(9,18)$, and of tactile stimuli on appearance or continuation of physiological and behavioural responses connected with brooding and care of young $(2,6,11,15)$.

The aim of this experiment was to investigate the chicks' ability to promote maternal responses in two distinct situations. During day exposure hens were first presented with one set of stimuli (i.e. visual, auditory and possibly tactile) and during night exposure hens were first presented with another set of stimuli (i.e. auditory and tactile). Hens presented with these two procedures showed different responses.

\section{Methods}

Subjects and maintenance. We used adult 'Vedette JV 15 ' hens (a heavy dwarfed strain) from an industrial breeding centre. None had previous maternal experience. Each hen was placed separately in a wire-latticed cage $(100 \times 70 \times 60 \mathrm{~cm})$ with opaque lateral partitions and wooden nests $(40 \times 30 \times 40 \mathrm{~cm})$. Each animal was thus isolated visually but not auditorily from the others. Temperature in the experimental chamber was $22^{\circ} \mathrm{C} \pm 2^{\circ} \mathrm{C}$. Animals were under a constant artificial photoperiod (15L:9D). The hens were layers when they arrived in the laboratory, but laying was stopped artificially by using a conventional food restriction method (20): food was withheld for seven days and water witheld concurrently during the first three days. After this deprivation period, the hens were fed unrestricted amounts of corn.

Experimental groups and protocol. Two groups were tested. The day group included 28 hens submitted to the 'day exposure' protocol. This treatment consisted of introducing two newborn chicks into each cage at the beginning of the diurnal phase of the photoperiod on day 1 . The night group consisted of 17 hens submitted to the 'night exposure' protocol. On day 0 , when lights were switched off, the hens were shut up in their 
nest-boxes and two hours later, two newborn chicks were placed under each hen as gently as possible. The following morning, 30 minutes before the lights were switched on, the nest-box doors were taken away to allow free access to the whole cage.

In both groups, chicks were replaced under the hen in the nest-box during the nights between days 1 and 2 and between days 2 and 3 , so that the chicks kept warm during the night. Wounded or killed chicks were replaced with chicks of the same age.

Observations and auditory tests. Detailed observations were made on days 1, 2 and 3 during daylight hours. Each animal was observed during $30 \mathrm{~s}$ every 18 min. During each sampling the following items were recorded: (i) distance between hen and chick; (ii) vocalizations, especially maternal calls, such as cluckings and food calls ('tidbits') (4); (iii) type of activity (e.g. resting, preening, feeding).

Auditory tests were made on days 4,6 and 10 in a dark room $(210 \times 210 \times 280 \mathrm{~cm})$. During two minutes, the hen's clucks in response to chicks distress calls played back from a tape were counted.

\section{Results}

Variations in behavioural responses during the three days of observation for the two experimental groups are presented in Tables 1 and 2. Aggressive behaviour decreased gradually with time in both experimental groups, but the overall level of aggressive acts was always higher in day group hens. In this group the level of physical contact between hen and chicks was low on day 1 but increased significantly later. On the contrary, night group hens immediately presented a high contact level which tended to decline from day 3 on. Maternal calls appeared gradually in both groups. Tidbitting appeared before clucking. Again day group hens began to emit maternal calls later than night group hens.

Further analysis is presented in Figure 1; each observation day is divided into three equal parts. This figure shows the decisive influence of nocturnal separation between days of observation on the improvement of maternal performance.

The results of the auditory tests are presented in Figure 2. The number of clucks was significantly higher by night group hens on day 4 (Mann-Whitney two-

TABLE 1

PERCENTAGES OF HENS PERFORMING AGGRESSION

AND MATERNAL CALLING

\begin{tabular}{|c|c|c|c|c|}
\hline & & Day 1 & Day 2 & Day 3 \\
\hline \multicolumn{5}{|l|}{ Aggression: } \\
\hline \multirow{3}{*}{ Pecks } & Day group & $\begin{array}{c}71.4 \% \\
* *\end{array}$ & $25 \%$ & $3.6 \%$ \\
\hline & Night group & $29.4 \%$ & $0 \%$ & $0 \%$ \\
\hline & Day group & $50 \%$ & $14.3 \%$ & $0 \%$ \\
\hline Wounder, Kill & Night group & $17.6 \%$ & $0 \%$ & $0 \%$ \\
\hline \multicolumn{5}{|l|}{ Maternal calls: } \\
\hline \multirow{2}{*}{ Tidbitting } & Day group & $\begin{array}{c}14.3 \% \\
* *\end{array}$ & $64.3 \%$ & $89.3 \%$ \\
\hline & Night group & $58.8 \%$ & $82.3 \%$ & $88.2 \%$ \\
\hline \multirow{2}{*}{ Clucking } & Day group & $\begin{array}{c}3.6 \% \\
*\end{array}$ & $25 \%$ & $46.4 \%$ \\
\hline & Night group & $23.5 \%$ & $47.1 \%$ & $64.7 \%$ \\
\hline
\end{tabular}

* Fisher exact probability test $(\mathrm{P}<0.05)$

** Fisher exact probability test $(\mathrm{P}<0.01)$ 


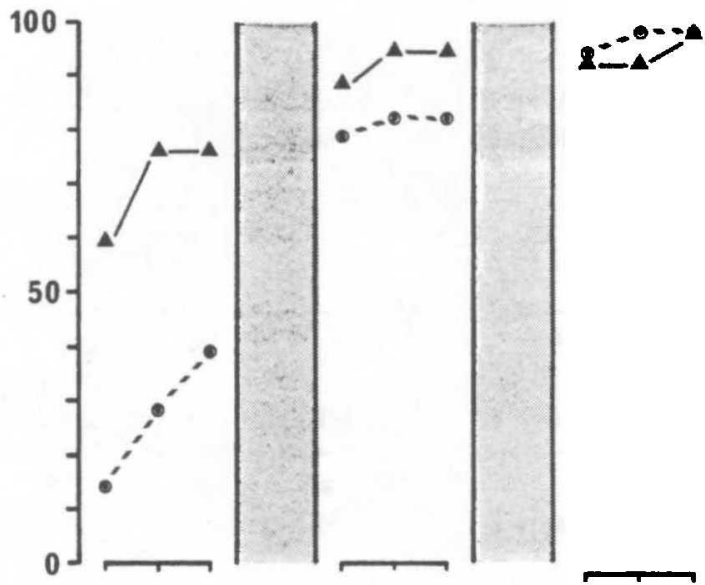

\section{Contact}

- Day group

- Night group

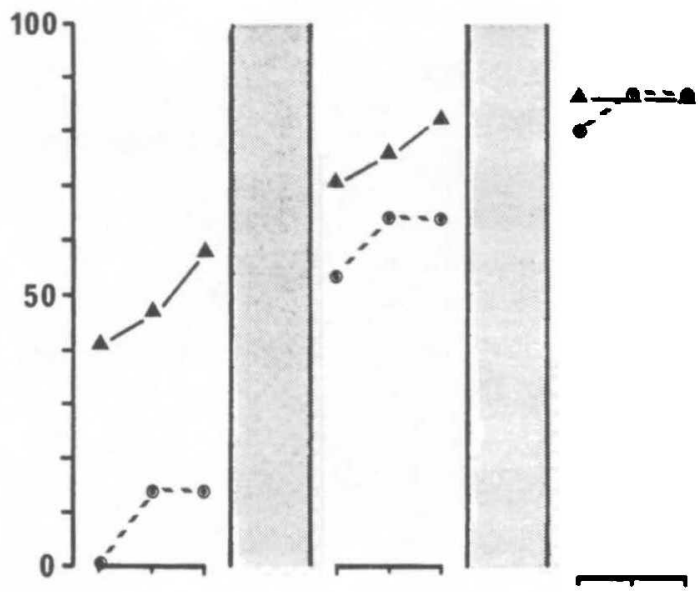

Tidbit

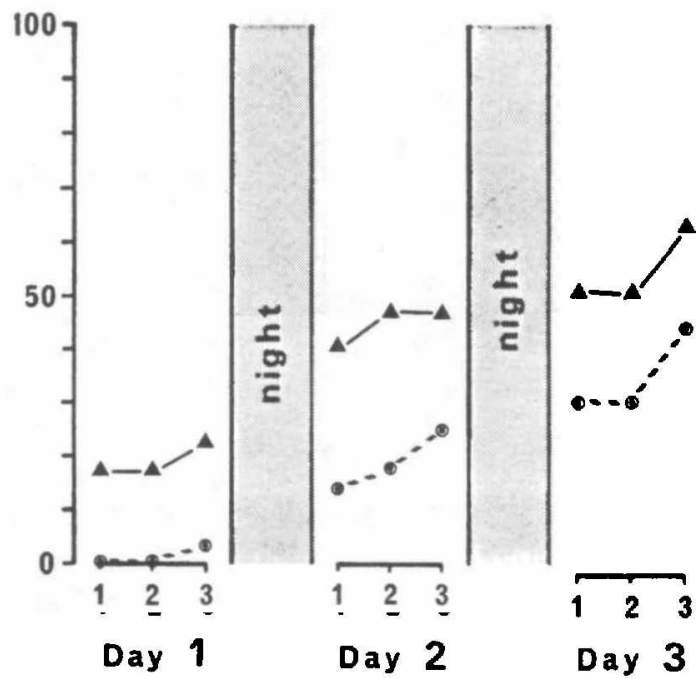

\section{Cluck}

Figure 1. Cumulative percentage of hens in the two experimental groups that displayed three behavioural responses (physical contact $>50 \%$ of records, tidbit and cluck) during three observation days. Each day was divided into three equal parts (of 15 records each). 
TABLE 2

AMOUNT OF PHYSICAL CONTACT BETWEEN HENS AND CHICKS ( $\check{X} \pm S E$ ) DURING THE THREE OBSERVATION DAYS

\begin{tabular}{|c|c|c|c|c|c|c|}
\hline & Day 1 & & Day 2 & & Day 3 & $\begin{array}{l}\text { Friedman test } \\
\left(X^{2}+\text { and } P\right)\end{array}$ \\
\hline Day Group & $\begin{array}{c}29.4 \pm 6.3 \\
\text { (b) }\end{array}$ & (a) & $67.9 \pm 5.9$ & & $\begin{array}{c}68.3 \pm 2.9 \\
\text { (b) }\end{array}$ & $10.5 P<0.01$ \\
\hline Night group & $61.8 \pm 8.8$ & & $67.4 \pm 4.5$ & (a) & $45.1 \pm 4.4$ & $8.9 P<0.05$ \\
\hline
\end{tabular}

(a) significant difference between successive days (Wilcoxon two-tailed test: $P<0.01$ )

(b) significant difference between two groups (Mann-Whitney two-tailed test: $P<0.01$ )

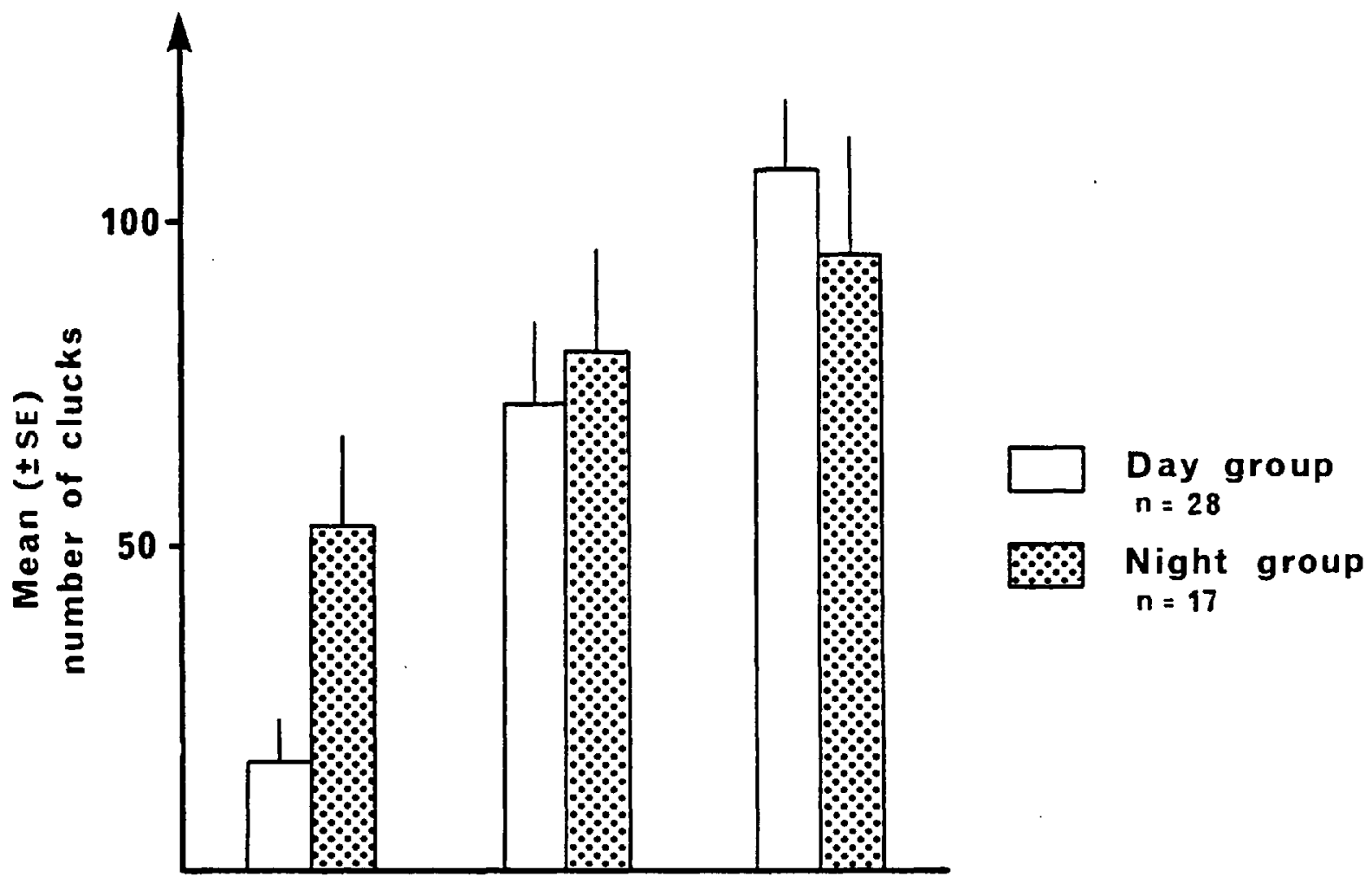

\section{Day 4 Day 6 Day 10}

Figure 2. Variations in number of clucks recorded during auditory tests.

tailed test: $P<0.02$ ), but no difference was found between the two groups on days 6 and 10 . Within each group, variation in number of clucks during auditory tests was significant (Friedman test: $\mathrm{X}_{r}^{2}=36.01, \mathrm{P}<$ 0.001 for day group; $\mathrm{X}_{\mathrm{r}}^{2}=10.3, \mathrm{P}<0.01$ for night group). The mean number of clucks increased significantly in both groups between day 4 and day 6 (Wilcoxon two-tailed test: $P<0.002$ for day group and $P<$ 0.05 for night group) and again between day 6 and day 10 in hens from the day group $(P<0.02)$. 
Correlations between quantifiable elements recorded during observations and quantifiable elements from auditory tests were investigated. A positive correlation between the amount of contact recorded on the first day of observation and number of clucks counted on day 4 was found $\left(r_{s}=0.37, N=28, P<0.05\right.$ for day group hens; $r_{s}=0.48, N=17, P<0.05$ for night group hens). This confirms that, on the whole, hens which accept chicks sooner also cluck sooner.

\section{Discussion}

The results of this experiment confirm previous reports $(11,14)$ that it is possible to induce a rapid onset of maternal responses in hens outside their normal reproductive cycle. However, it is evident that the experimental situation influences the appearance of these responses. When chicks were placed in a hen's cage at the beginning of the day, they were perceived as intruders: hens avoided or attacked them. However, after some delay, adults tolerated contact with young. Then, brooding behaviour appeared; later, one after the other, the two typical maternal calls (tidbitting and clucking) appeared. Finally, hen behaviour changed from rejection, which lasted on average one day, to care and protection of chicks. When chicks were placed under hens at the beginning of the night, a period of rejection was observed only in very few subjects. Maternal responses appeared on day 1 in the majority of subjects. These results show the importance of nocturnal pre-exposure to chicks on the delay of appearance of maternal behaviour. Similarly, in hens presented chicks at the beginning of the day, maternal performance improved after night exposures (Figure 1). It should be stressed that in these animals behavioural responses observed on day 2 were almost identical to those recorded on day 1 in night groups hens (Tables 1 and 2 ). This lag was also found the following day.

The quicker establishment of maternal behaviour in hens induced during night supports previous work (3) concerning external factors facilitating maternal responses (e.g. darkness, restricted space), and agrees with experimental results showing the crucial role of ventral tactile stimulation in the establishment of maternal behaviour $(11,15)$. Under natural conditions, auditory stimulations from hatching chicks occur before visuat interactions between parents and young and further facilitate chick adoption (9). The night exposure provided stimulation (i.e. tactile, auditory and only later visual) comparable to natural brooding and hatching.
Another point that should be mentioned is that in the night group, as chicks get older, contact between hens and chicks declines; a significant drop is observed as soon as day 3 (Table 2). These results are in line of those of several authors working on natural broods (1, $5,17)$ and may reflect the maturation of chicks' thermoregulation (17). By contrast, in day group, in which maternal responses appear later, the amount of contact between hens and chicks does not decline with time, on day 3 it is higher than in night group.

The hypothesis that maturation of thermoregulation is altered when the hen does not display full maternal behaviour, particularly brooding, cannot be discarded. However, another explanation is possible. Many experiments have shown that young actively attempt to be near the mother or surrogate mother independently of the mother's ability to give heat or food. It may be necessary for young to seek security near an attachment object before engaging in more diversified activities $(7,19)$.

The experiment described here helps specify modalities of establishment of the relationships between mother and young in the domestic hen. Further experiments are necessary to quantify the minimum time of physical contact at night needed to hasten the appearance of maternal responses.

\section{References}

1. Bateson, P.P.G. 1973. The imprinting of birds. In: Ethology and Development. Edited by S.A. Barnett. London: Heineman Medical Books Lid.

2. Buntin, J. D. 1977. Stimulus requirements for squabinduced crop sac growth and nest acceptation in ring doves (Streptopelia risoria). Journal of Comparative and Physiological Psychology 91: 17-28.

3. Burrows, W.H. and T.C. Byerly. 1938. The effect of certain groups of environmental factors upon the expression of broodiness. Poultry Science 17: 324-330.

4. Collias, N. and M. Joos. 1953. The spectographic analysis of sound signals of the domestic fowl. Behaviour 5: $175 \cdot 187$.

5. Guyomarc'h, J.C. 1975. Les cycles d'activité d'une couvée naturelle de poussins et leur coordination. $\mathrm{Be}$ haviour 53: 31-75.

6. Hall, M.R. and A.R. Goldsmith. 1983. Factors affecting prolactin secretion during breeding and incubation in the domestic duck (Anas platyrhynchos). General and Comparative Endocrinology 49: 270-276.

7. Harlow, H.F. 1959. Love in infant monkeys. In: Readings from Scientific American, Animal Behavior. San Francisco: Freeman and Company. 
8. Hinde, R.A. 1965. Interaction of internal and external factors in integration of canary reproduction. In: Sex and Behaviour. Edited by F.A. Beach. New York: Wiley.

9. Impekoven, M. 1976. Prenatal parent-young interactions in birds and their long-term effects. In: Advances in the Study of Behavior. Edited by J.S. Rosenblatt, R.A. Hinde, E. Shaw and C. Beer. New York: Academic Press.

10. Lehrman, D.S. 1964. The reproductive behavior of ring doves. In: Reading from Scientific American, Animal Behavior. San Francisco: Freeman and Company.

11. Maier, R.A. 1963. Maternal behavior in the domestic hen; the role of physical contact. Journal of Comparative and Physiological Psychology. 56: 357-361.

12. Mayer, A.D. and J.S. Rosenblatt. 1975. Olfactory basis for the delayed onset of maternal behavior in virgin female rats: Experiential effects. Journal of Comparative and Physiological Psychology 89: 701-710.

13. Poindron, P. and P. Le Neindre. 1980. Endocrine and sensory regulation of maternal behavior in the ewe. In: Advances in the Study of Behavior. Edited by J.S. Rosenblatt, R.A. Hinde, C. Beer and M.C. Busnel. New York: Academic Press.

14. Richard-Yris, M.A., D.H. Garnier and G. Leboucher. 1983. Induction of maternal behavior and some hormonal and physiological correlates in the domestic hen.
Hormones and Behavior 17: 345-355.

15. Richard-Yris, M.A. and G. Leboucher. 1986. Comportement maternel induit chez la poule domestique: Influence d'une séparation partielle ou totale sur le maintien de la réactivité maternelle. Comptes rendus de l'Académie des Sciences Paris, 302, série III, 10: 387-390.

16. Rosenblatt, J.S., H.I. Siegel and A.D. Mayer. 1979. Progress in the study of maternal behavior in the rat: Hormonal, nonhormonal, sensory and developmental aspects. In: Advances in the Study of Behavior. Edited by J.S. Rosenblatt, R.A. Hinde, C. Beer and M.C. Busnel. New York: Academic Press.

17. Sherry, D.F. 1981. Parental care and the development of thermoregulation in red junglefowl. Behaviour 76: 250 279.

18. Tuculescu, R.A. and J.G. Griswold. 1983. Prehatching interactions in domestic chickens. Animal Behaviour 31: 1-10.

19. Vidal, J.M. 1976. Empreinte filiale et sexuelle. Réflexions sur le processus d'attachement d'après une étude expérimentale sur le coq domestique. Thèse Doctorat d'Etat. Université de Rennes I.

20. Wilson, H.R., W.G. Nesbeth, C.R. Douglas and E.R. Miller. 1979. Forced resting bobwhite quail breeders and their subsequent reproductive performance. Poultry Science 58: 731-737. 